\title{
EL MOVIMIENTO OBRERO EN EL BAIX LLOBREGAT ENTRE 1970 Y 1975
}

\author{
Joaquín Beltrán Dengra
}

\section{Introducción ${ }^{1}$}

A finales de la década de los cincuenta se produjo un boom demográfico en el Baix Llobregat como consecuencia del reinicio del proceso industrializador que aconteció en Cataluña.

1. Este artículo trata la disensión del movimiento obrero en la comarca barcelonesa del Baix Llobregat entre los años 1970 y 1976 y es el resultado de una investigación que realicé hace dos años.

Los objetivos que me propongo son mostrar las diversas formas de lucha que los obreros fabriles de la mencionada comarca llevaron a término, la cuantificación de las huelgas y los trabajadores involucrados en ellas, los tipos de demandas y lo que consiguieron.

Engarzo el discurso, los fines y los métodos de la organización socio-política y obrera clandestina más importante de aquellos años en Cataluña: Comisiones Obreras (CCOO) y las formas concretas de llevarlos a la práctica en el Baix Llobregat. También muestro la visión de las diferentes tendencias ideológicas y políticas de las distintas corrientes de esa organización clandestina, sus tácticas y estrategias.

Para la redacción me he basado, fundamentalmente, en fuentes escritas directas: prensa obrera, panfletos, boletines, informes sobre elecciones sindicales, negociación y conflictos colectivos encontrados en el Archivo Nacional de Cataluña, en adelante ANC, en el Archivo histórico comarcal de Sant Feliu de Llobregat (fons Xavier Valldeneu), en el Centro de Documentación-Fundación Utopía Joan N. García-Nieto, en el Archivo histórico de la CONC (Confederación Obrera Nacional de Cataluña) y en el Archivo de Cervera.

También me he basado en entrevistas a líderes obreros de aquellos años que sirven para aclarar y añadir aspectos que las fuentes escritas directas e indirectas omiten o tratan con opacidad.

La bibliografía consultada es pequeña porque el artículo sólo versa sobre el Baix Llobregat.

He eludido tratar El Prat de Llobregat porque ya ha sido estudiado por S. Bengoechea y M. Renom, Memòria i compromís. Classes treballadores, sindicalisme i política al Prat de Llobregat (1917-1979), Barcelona, Columna, 1999.

He incluido el Municipio de Esplugues porque está soldado con el Baix Llobregat y forma una unidad con él. 
En el Baix Llobregat se ubicaron muchas industrias debido al bajo precio del suelo y a la proximidad con Barcelona. El reducido precio del suelo fue motivo, también, de la construcción de numerosas viviendas que dieron cobijo a los recién llegados.

Entre los años 1950 y 1975 la población de la mencionada comarca aumentó un $380 \%$, siendo los años sesenta los más acrecentados: la población se incrementó en un $126 \%$.

La evolución de la población en el Baix Llobregat, entre los años 1950 y 1975, fue la siguiente:

Crecimiento poblacional en el Baix Llobregat ${ }^{2}$

$\begin{array}{lr}1950 & 96.625 \\ 1960 & 155.361 \\ 1970 & 348.948 \\ 1980 & 462.648\end{array}$

La inmigración tuvo gran importancia para entender el crecimiento demográfico de la comarca: fue el primer factor de la expansión de la población. Entre 1961 y 1965 representó el 63\% del incremento total poblacional. Entre 1966 y 1970 el $58 \%$. Y entre 1971 y 1975 el $43 \%$.

Los inmigrantes del Baix Llobregat fueron, en su gran mayoría, andaluces, a continuación les siguieron los extremeños y después los murcianos.

La consecuencia del aumento demográfico fue el crecimiento urbano. Este crecimiento introdujo (en los años 1960 y 1970) desequilibrios profundos en el conjunto del hábitat: escasez o ausencia de equipamientos y servicios, sobre todo, en los suburbios que se formaron en la periferia de los municipios.

El Baix Llobregat registró los mayores déficits de las comarcas industrializadas (juntamente con el Vallés Oriental) en pavimentación, iluminación de las calles, cloacas y en equipamientos escolares y sanitarios ${ }^{3}$.

La mayoría de la población, en edad de trabajar, lo hizo en la industria. Ésta empleó, en 1975, al 51'9\% de la población activa (el total para Cataluña, en ese año, fue del $39^{\prime} 37 \%$ ).

En el Baix Llobregat sobresalieron las empresas medianas (aquéllas que ocupaban entre 101 y 500 trabajadores), pero también fueron importantes las empresas pequeñas (las que daban trabajo a un máximo de 100 obreros).

2. G. Cortés y M. del Mar Isla, El procés de creixement al Baix Llobregat en "Arrel", no 2, gener-abril de 1982, p 20.

3. Así lo señalan G. Cortés y M. del Mar Isla, op., cit., pp. 29-31. 
Los sectores industriales que proporcionaron más trabajo fueron el siderometalúrgico (con predominio de las empresas medianas y grandes), la construcción (con supremacía de las empresas pequeñas), la química (en ella tenían importancia las empresas medianas y grandes) y el textil (en este sector predominó la empresa mediana).

La inmigración tuvo una importancia capital en el desarrollo y el carácter del movimiento obrero: la mayoría de los líderes obreros del Baix Llobregat fueron inmigrantes; aunque no todos (ello estuvo relacionado con el lugar que ocuparon en el proceso productivo, ya que tuvieron las profesiones menos calificadas y peor pagadas); sus ocupaciones laborales fueron menos calificadas que la de los nativos. En Cornellá, que fue el municipio más industrializado del Baix Llobregat, la población ocupada a partir de los16 años (según los padrones municipales de 1986) fue la siguiente ${ }^{4}$ :

$\begin{array}{lrrcr} & \text { nacidos en Cataluña } & \text { nacidos en el resto de estado } \\ \begin{array}{l}\text { Profesionales y } \\ \begin{array}{l}\text { Técnicos } \\ \text { Servicios }\end{array}\end{array} & 901 & 13^{\prime} 07 \% & 995 & 8^{\prime} 08 \% \\ \begin{array}{l}\text { administrativos } \\ \begin{array}{l}\text { Comerciantes y } \\ \text { Vendedores }\end{array}\end{array} & 152 & 2^{\prime} 20 \% & 128 & 0^{\prime} 78 \% \\ \end{array}$

La inmigración instalada en este municipio, y por extensión en todo el Baix Llobregast, tuvo un carácter exclusivamente industrial. Los trabajadores foráneos que llegaron, entre 1960 y 1970, se ocuparon básicamente en las actividades industriales poco tradicionales, mientras que los nativos se ocuparon más en las industrias tradicionales, como la textil.

La situación económica de los trabajadores inmigrantes (de todos en general, aunque los nativos estaban mejor pagados) fue difícil. En las páginas 183 y 184 de mi Tesis Doctoral se puede leer que los trabajadores inmigrantes que llegaron a Cornellá (y por extensión a todo el Baix Llobregat) a partir de los años 1960 procedían de zonas rurales (casi todos habían sido obreros agrícolas en sus lugares de origen) y, por consiguiente, al llegar aquí ocuparon los últimos lugares en el proceso productivo; la casi totalidad de ellos trabajaron de peones y/o especialistas. Esas ocupaciones se caracterizaron por tener bajos salarios, que tuvieron que compensar con el trabajo extraordinario (horas extras), primas de productividad, larga duración de la jornada laboral (en aquellos años era de 48 horas semanales, pero muchos de ellos trabajan hasta 12 horas diarias) y pocos días de vacaciones.

4. Cfr. en J. Beltrán Dengra, Una aproximación al estudio socio-cultural de la inmigración en elÁrea de Barcelona: Demografía y Urbanismo, Cornellá: 1940-1986, Tesis Doctoral, Barcelona, Facultad de Geografía e Historia de la Universidad central de Barcelona, 1995, p. 119.

Este censo, a pesar de ser de 1986 sirve para aseverar que los trabajadores inmigrantes ocuparon los trabajos menos calificados. 
Respecto a la situación económica hay que señalar la alta tasa de inflación que se dio durante el primer quinquenio de los años setenta. En 1971 los precios subieron el 8'2\%, en 1972 el 8'3\%, en 1973 el $11^{\prime} 4 \%$, en 1974 el $15^{\prime} 7 \%$ y en 1975 el $17 \%{ }^{5}$. El gobierno, para contener la inflación, congeló los salarios en noviembre de 1973, un mes después del incremento de los hidrocarburos. Esta medida indignó a los trabajadores, que incrementaron sus acciones de protesta.

En 1974 llegó la recesión económica, y, en consecuencia, en Barcelona y su provincia muchas empresas cerraron En ese año 111 fábricas suspendieron sus pagos y otras presentaron expediente de crisis. En 1975 las empresas que presentaron expediente de crisis ascendieron a $735^{6}$.

El resultado de esta recesión fue la pérdida del poder adquisitivo de los trabajadores, a pesar del aumento de los salarios, por el descenso de las horas extra, la disminución de las primas de producción y el retroceso del empleo.

\section{Objetivos, estrategia y reivindicaciones de CCOO. en 1970 y 1971}

Los días 30 y 31 de mayo de 1970 tuvo lugar la séptima reunión nacional de CCOO de Cataluña . En ella se advirtió la necesidad de hacer más esfuerzos para involucrar a más trabajadores en las luchas obreras y se acordó combinar los métodos legales con las acciones extralegales; también se juzgó importante prestar atención a los convenios colectivos porque, a través de éstos, se podían movilizar a los trabajadores e incrementar su conciencia social.

En esta reunión se convino la necesidad de incorporar las reivindicaciones políticas a las luchas obreras para acabar con la dictadura e instaurar la democracia parlamentaria, estableciendo en ella un sindicato de clase, unitario, democrático e independiente.

Se determinó presentarse a las próximas elecciones sindicales (acontecieron en julio de 1971) porque así se defendían mejor a los trabajadores:

Se trata de aprovechar, una vez más, las posibilidades legales, librando una batalla contra los verticalistas; por el desplazamiento de los domésticos de la patronal; Ilevando a los puestos de enlaces, jurados y miembros de las juntas

5. B. de Riquer y J. B. Culla, El franquisme i la transició democrática [1939-1988], ("Historia

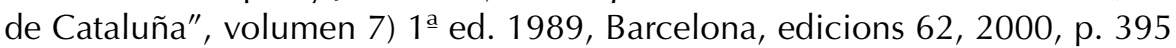

6. ibidem

7. nació en 1966 bajo el patrocinio del Partido Socialista Unificado de Cataluña (era el Partido Comunista en Cataluña, pero independiente del PCE), en adelante PSUC. La constitución de $\mathrm{CCOO}$ de Cataluña tuvo lugar en le Iglesia de San Medir (Barcelona) el 20 de noviembre de 1964 
sociales $^{8}$ a trabajadores honrados, conscientes y combativos, que estén dispuestos al sacrificio que la defensa de los intereses que la clase obrera exige ${ }^{9}$.

Se acordó que era necesario celebrar asambleas dentro y fuera de los centros de trabajo para que los trabajadores defendieran sus derechos económicos, sociales y políticos. Las reivindicaciones surgidas de las asambleas debían ir acompañadas de medidas de fuerza como la realización de paros, boicot a las horas extras, disminución del rendimiento, recogidas de firmas y manifestaciones; opinaban que sólo recurriendo a esos métodos se podían conseguir las demandas obreras.

En enero de 1971 la comisión de la coordinadora de CCOO de Cataluña reiteró lo acordado en la séptima reunión nacional, juzgando necesario ,al mismo tiempo, coordinar las luchas obreras e ir a la huelga general en demanda de un salario no inferior a 400 ptas.día $^{10}$, de la jornada de 40 horas semanales, del $100 \%$ del salario real para los jubilados y pensionistas, por el derecho de asamblea, por la reducción de la inflación, contra los despidos, por un sindicato de clase, contra la represión, por la disolución de la brigada político social, contra el estado de excepción en Guipúzcoa, por la anulación de las jurisdicciones especiales, tribunales militares y de orden público y por la amnistía para todos los presos y exiliados políticosociales ${ }^{11}$.

El 26 de abril de 1971 CC.OO del Baix Llobregat apeló a los trabajadores de la comarca a que participaran en las elecciones sindicales, potenciando, de esa manera, las CC.OO y luchar para instaurar un sindicato de clase, dentro de un régimen democrático parlamentario.

8. el enlace sindical era el representante de los trabajadores. Lo votaban los trabajadores de la fábrica. Se encargaba de recoger las aspiraciones económicas y laborales de los trabajadores reunidos en asamblea.

Los enlaces sindicales elegían al jurado de empresa, que era quien se reunía con la dirección de la empresa para presentarle las reivindicaciones obreras.

Las juntas sindicales iban por ramos industriales: textil, metal, química, etc. Su número era proporcional al número -de enlaces sindicales- representantes por ramos industriales y localidades. Los elegían todos los enlaces sindicales del mismo sector industrial. Negociaban el convenio de todas las empresas que pertenecían al mismo ramo industrial.

9. CC.OO de Cataluña, 30 y 31 de mayo, v. en ANC, Remei Ramírez Viadé, en adelante $R M V$.

10. en 1969 el salario diario medio en Cataluña era de 181'46 ptas.. cfr. J. Jané, Els salaries a Catalunya. Estructura i evolució a la década dels seixanta, citado por B. de Riquer y J. B. Culla, op. cit, p. 341.

11. Comisión de la coordinadora de las comisiones obreras de Cataluña, enero de 1971, v. en $\mathrm{ANC}, \mathrm{RMV}$. 


\section{La disensión sindical en el Baix Llobregat en 1970 y 1971}

La organización que más importancia tuvo en la disputa con CCOO del Baix Llobregat ${ }^{12}$ (en la cual habían muchos militantes del PSUC) para hegemonizar las luchas obreras en la década de los setenta fue Bandera ${ }^{13}$. Esta organización estuvo en contra de los convenios porque significaban una merma económica para los trabajadores (dijo que la inflación invalidaba las subidas salariales) y un aumento de la explotación al exigirse un incremento de la productividad. También opinó que los convenios de empresa obstaculizaban las luchas obreras comunes entre las diferentes empresas y dividían a los trabajadores de la misma fábrica porque se estipulaban diferencias salariales entre las categorías profesionales.

Se pronunciaron en contra de utilizar los espacios legales como estrategia por considerarlos estériles. Abogaron por extender las luchas obreras a todas las fábricas posibles y fomentar las asambleas de fábricas, creándose para ello una comisión obrera que las impulsara ${ }^{14}$.

Esta formación fundó, en el verano de 1971, su propia organización obrera de base dentro de CCOO: la coordinadora de sectores. Fue una tendencia que estuvo dentro de CCOO y se propuso ser la alternativa a las CCOO dominadas por militantes del PSUC, aunque en CCOO también militaron trabajadores independientes y católicos.

De todos modos, quien continuó teniendo la supremacía en las luchas obreras fabriles fue el sector mayoritario de CCOO del Baix Llobregat, que estaba compuesto-mayoritariamente- por militantes del PSUC ${ }^{15}$, aunque no todos estaban en ese partido político. A este respecto, Francisco Ruiz Acevedo ${ }^{16}$ dice que: "Bandera Roja tuvo poca relevancia en el movimiento obrero. Sólo adquirió alguna notoriedad a finales de 1974. Crearon un comisión Ilamada coordinadora de barrios y fábricas e hicieron un gran trabajo en el movimiento asociativo".

12. nacieron en otoño de 1965 en la Iglesia del barrio Almeda de Cornellá y su misión fue coordinar las luchas obreras de la comarca

13. surgió en 1968. Tenía una ideología centrista, esto es: estaba entre el PSUC y la izquierda más radical. Sin embargo,la mayoría de sus militantes ingresaron en el PSUC en 1974; y desde ese momento defendieron el eurocomunismo.

14. cfr. “¿Cómo luchar contra los próximos convenios?" en prensa obrera, no 1 , octubre 1971; y Agencia Popular Informativa (en adelante API), nº 11, 1972.

15. cfr. J. Tardà y P. Carrión, 40 anys d'una ciutat. Cornellà de Llobregat durant el franquisme, Cornellá, Exprés Serveis, 1992, p. 209. y S. Bengoechea y M. Renom, op. cit., cap. 6. Estas historiadoras dicen que Bandera Roja tuvo mucha importancia en las fábricas "La seda" y "Pianelli", ubicadas en El Prat de Llobregat.

16. fue activista de la empresa Rockwell-Cerdans, S.A. También fue presidente de la Unión de Técnicos Trabajadores de Gavá. Perteneció al PSUC y a CCOO. 
Joan Tardà y Pedro Carrión ${ }^{17}$ dicen que esa organización comunista integró mucha militancia joven, que fueron al mismo tiempo trabajadores y estudiantes. Opinan, también, que fueron los impulsores de la actividad reivindicativa en los barrios.

Paco Arias $^{18}$ dice que:

En 1968 nació Bandera Roja (yo fui uno de los que la fundaron, junto con Joan García-Nieto, Alfonso Carlos Comín,....) [...]. Estuvo compuesta, en su gran mayoría, por jóvenes de entre 20 y 25 años. Surgió porque CC.OO.. se quedó un poco rezagada por culpa de la represión. Esta organización dio un empujón a las asociaciones de vecinos.

Se puede decir, a modo de conclusión, que Bandera Roja tuvo una cierta implantación fabril en el Baix Llobregat, sobre todo a partir de 1974, ya que logró atraer a decenas de jóvenes obreros de factorías locales; pero donde más arraigo tuvo fue en el mundo asociativo, como las comisiones de barrio.

El resto de los partidos de izquierda fueron minoritarios y su influencia en la comarca fue muy reducida porque estuvieron muy fragmentados. No quisieron penetrar en las estructuras de base del sindicato franquista con el objetivo de forzar una alternativa sindical revolucionaria o democrática; y que era donde iban la mayoría de los trabajadores cuando tenían problemas, pues tenían miedo de moverse en la clandestinidad, que es lo que propugnaban esos partidos, por la represión existente ${ }^{19}$.

\section{Conflictividad laboral entre 1970 y $1973^{20}$}

A partir de 1970 la conflictividad laboral en el Baix Llobregat fue mayor. José Cano ${ }^{21}$ dice que:

A partir de 1970 hubo más huelgas solidarias en la comarca. A partir de ese año el número de obreros que participaron en paros solidarios con otras fábricas

17. op.cit., p. 210 .

18. fue activista de la empresa Pirelli-Moltex y uno de los fundadores de CCOO del Baix Llobregat. Perteneció al Bandera Roja, al PSUC y a CCOO.

19. La Liga Comunista Revolucionaria editó en 1970 la revista proletario. Se opusieron a participar en las elecciones sindicales de 1971, abogando por el abandono de la legalidad como estrategia. Se posicionó a favor de la creación de una central obrera roja, cuyo objetivo sería realizar la revolución socialista, cfr. Proletario, portavoz de los obreros revolucionarios del Bajo Llobregat, 1970, no 1 y 2 .

20. para estudiar la conflictividad laboral desde 1970 hasta 1975 me he valido de la prensa proletaria fabril clandestina de aquellos años, así como de panfletos, boletines y documentos ilegales encontrados en algunos archivos.

21. fue representante del sindicato metalúrgico de San Feliu y activista de la empresa Matacás. Perteneció al PSUC y a CCOO. 
fue mayor. En los paros se unieron las reivindicaciones propias con las de solidaridad para con los compañeros de otras fábricas".

A partir de ese año hubo un cambio cualitativo en las luchas obreras: se incorporaron las reivindicaciones políticas. A este respecto Esteban Cerdán $^{22}$ (preguntado por la resonancia que tuvieron las demandas políticas entre los obreros) contestó:

A los todos las trabajadores se les llegó más con las reivindicaciones laborales que con las políticas. CC.OO. puso más énfasis en las reivindicaciones sociales y económicas: mejor vestuario, calefacción, agua caliente, mejor salario... porque los obreros se movían más por estas demandas. A partir de ahí se fueron añadiendo las demandas políticas. Al final ambas reivindicaciones fueron juntas.

Ante la misma pregunta, José Cano contestó: "Ios trabajadores respondieron más a las reivindicaciones laborales que a las políticas, pero muchos de ellos (entre el $40 \%$ y el $50 \%$ de las plantillas) colaboraron en recolectas y firmas para ayudar a los obreros despedidos".

Desde febrero de 1970 hasta agosto del mismo año participaron en las distintas acciones reivindicativas 12.000 trabajadores, se hicieron 49 asambleas (25 en el sindicato y 24 en las fábricas) y 2 concentraciones y se produjeron 13 paros. El motivo principal de esas acciones reivindicativas fue la renovación o iniciación del convenio colectivo. Las formas de lucha que más destacaron fueron las huelgas de horas extra y los bajos rendimientos.

En ese año se renovó el nuevo convenio del metal que afectó a 11.000 trabajadores y a 400 empresas. La comisión deliberadora (formada por enlaces de las fábricas Norma Galindo, Roca, Soler Almirall, Telexco, Matacás, Laforsa, Siemens, Adaibra, Talleres Falcó y García Molla) presentó una plataforma con las siguientes demandas: 44 horas semanales, jornal entero en caso de accidente o enfermedad, 426 ptas. diarias para el peón con 2 hijos, 3 pagas de 30 días completos, 20\% de bonificación al año para los trabajos tóxicos y un año de duración del convenio; pero sólo se consiguió, por norma de obligado cumplimiento, el $6{ }^{\prime} 5{ }^{23} .^{23}$.

CCOO del Baix Llobregat se propuso tomar contacto con los trabajadores más combativos de las fábricas en conflicto para crear o consolidar en ellas las

22. fue activista de la empresa Alforza y vicepresidente del sindicato del metal de Cornellá. Perteneció al PSUC y a CCOO.

23. El salario diario de un peón de la empresa Siemens era en 1971 de 225 pesetas. Tenían 22 días de vacaciones anuales, 2 pagas 30 días completos y trabajaban 48 horas semanales. El Salario diario de un peón de la empresa Soler Almirall era en 1972 de 292 pesetas. Tenían 22 días de vacaciones anuales, 2 pagas de 30 días y trabajaban 45 horas semanales. Sin embargo, las pequeñas empresas pagaban menos y y sus trabajadores trabajaban más días al año. Cfr. Delegación provincial de trabajo. Convenio colectivo sindical de la empresa Siemens, industria eléctrica, en "El Boletín Oficial de la Provincia", n.27, 1 de febrero de 1971, pp. 4-9;Delegación provincial de Trabajo. Convenio colectivo sindical de la empresa C. Soler Almirall, S.A., en "El Boletín Oficial de la Provincia", n. 153, 27 de junio de 1972, pp. 3-7. 
CCOO e intentar coordinar más las luchas y organizar, así, un movimiento de masas que sirviera para preparar la huelga general. A través de ésta pretendió conseguir un régimen político democrático-parlamentario, llevando, de esta manera, a término la política de pacto por la libertad del PSUC, que consistía en acabar con el franquismo a través de una gran presión organizada ${ }^{24}$.

En el año 1972 se renovaron muchos convenios colectivos: ese fue el motivo principal de la conflictividad laboral en el Baix Llobregat. Muchas fábricas hicieron paros para reivindicar mejoras laborales en sus convenios.

CCOO del Baix Llobregat creó en 1972 una coordinadora de todas la empresas en lucha o en situación conflictiva. La formaron las siguientes fábricas: Elsa, Pirelli, Fergat, Norma Galindo y Fenixbrón ${ }^{25}$.

El año 1973 empezó con las huelgas de los obreros de Corberó (empresa metalúrgica de Espulgues con 3.500 trabajadores) y de Tornillería Mata (empresa metalúrgica de Cornellá con 270 trabajadores). Los primeros estuvieron disconformes con las deliberaciones de su convenio: reivindicaron que sólo durara un año, aumento de 2.300 ptas. con 15 pagas anuales, 100\% del sueldo en caso de enfermedad o accidente laboral, unificación de los puestos de trabajo por categorías, exigencia de que los mandos intermedios y los jefes fueran correctos en su trato con los trabajadores y que todos los puntos ya conseguidos en el primer convenio por dos años quedaran fijos en el convenio por un año. La dirección sólo ofreció una subida salarial de 27.000 ptas. anuales. Sin embargo, la huelga empezó al despedir la empresa a diez trabajadores y duró una semana. Contaron con el apoyo de los obreros de las empresas Pirelli, Siemens, Tuperín, Plásmica, Fergat, Vitroiber y Benavent, que hicieron paros de algunas horas de duración y recolectas para solidarizarse con los trabajadores despedidos de Corberó y de Tornillería Mata.

Los trabajadores de Corberó volvieron al trabajo el 22 de enero sin conseguir la readmisión de los 10 despedidos. Los obreros de la empresa Mata tampoco consiguieron que los 131 compañeros despedidos fueron readmitidos ${ }^{26}$.

Los días 3, 4 y 5 de abril de 1973, con motivo del asesinato de un obrero en Sant Adrià del Besos, por parte de un policia, se realizaron paros parciales en algunas fábricas de la comarca; éstos fueron cuantiosos el día 6 al convocar CCOO del Baix Llobregat una huelga general. También se hicieron manifestaciones en los municipios de Molins de Rey, Sant Feliu, Sant Joan Despí y Cornellá. En algunas localidades de la comarca cerraron un setenta por ciento de bares y comercios ${ }^{27}$.

24. cfr. J. Solé Tura, "Unidad y diversidad en la oposición comunista al franquismo" en Josep Fontana (ed.) España bajo el franquismo, Barcelona, 1aㅡ ed. 1986, crítica, 2000, p. 134 .

25. cfr. en I. Riera y J. Botella, El Baix Llobregat. 15 años de luchas obreras, Barcelona, Blume, 1976, p. 85.

26. Esa huelga empezó como protesta por la detención, por parte de la brigada políticosocial, de un compañero; pero continuó al despedir la empresa a toda la plantilla.

27. I. Riera y J. Botella, op., cit., p.98. 
En junio de 1973 quedaron rotas la deliberaciones del convenio comarcal del ramo del metal. La plataforma reivindicativa de CCOO del Baix Llobregat fue la siguiente: salario de 450 ptas. diarias para el peón, semana de 40 horas, pagas extras de 30 días, 21 día laborales de vacaciones, salario íntegro en caso de enfermedad y ayuda escolar a los hijos. Al final se dictó una norma de obligado cumplimiento porque la patronal sólo estaba dispuesta a aceptar un aumento del $24 \%$ sobre el salario existente en el convenio vigente, lo cual sólo supuso 1.590 ptas. semanales para el peón.

Durante las negociaciones, de ese convenio, muchas empresas del ramo llevaron a cabo diversas formas de lucha; pero las que más destacaron fueron los paros. Éstos afectaron a 23 empresas, participando en ellos casi 30.000 trabajadores.

También hubieron paros solidarios para que se readmitieran a compañeros despedidos. Ese fue el motivo de la huelga que realizaron los trabajadores de Solvay (de Martorell), los de Emtisa (de Sant Andreu de la Barca) y los de Roca (de Gavá); aunque estos últimos también pararon para defender su plataforma reivindicativa en las deliberaciones que se estaban realizando en el convenio. Los trabajadores de Solvay (empresa perteneciente al sector químico ubicada en Martorell) demandaron 6.000 ptas. de aumento mensual, semana de 40 horas, $100 \%$ de salario en caso de enfermedad o accidente, IRTP a cargo de la empresa, 30 días de vacaciones, convenio por un año y derecho de huelga y asamblea; pero la dirección sólo concedió un aumento salarial de entre el 20\% y el 26\%, 24 días de vacaciones y dos años de duración del convenio.

Los trabajadores de Exín (empresa química de Molins de Rey, con 310 trabajadores) también estuvieron en desacuerdo con la empresa en las deliberaciones de su convenio. Pidieron un aumento mensual de 3.500 Ptas., la dimisión del jurado de empresa y la supresión de la contratación de trabajadores eventuales; pero la empresa sólo concedió un aumento salarial de 600 a 800 ptas. al mes. Fueron a la huelga por no llegarse a ningún acuerdo. A la semana siguiente, la dirección despidió a toda la plantilla. Se solidarizaron con su lucha algunas fábricas: Fundiciones Ros (de Sant Vicenç dels Horts) paró tres horas. Turbo (de Molins de Rey) paró / de hora. Contaron, también, con la solidaridad económica de algunas empresas. Sin embargo, los trabajadores de Exín no consiguieron lo que demandaron. Hubo despidos.

\section{Objetivos, estrategia y reivindicaciones de CCOO en 1974}

Después del asesinato del almirante Carrero Blanco, por parte de ETA, a finales de 1973 se hizo menos creíble la idea de que el régimen pudiera perpetuarse más allá de la muerte del dictador. Los dos años que separaron la muerte de Carrero Blanco y la del mismo Franco, en noviembre de 1975, estuvieron Ilenos de intrigas políticas; el régimen franquista padeció disensiones internas. 
Ante esta tesitura, la oposición comunista usó los movimientos de protesta como un ariete para derrumbar un régimen cuyos fundamentos sociales creía que se habían desquebrajado.

Por otra parte, la dirección del PCE forzó en Madrid la creación de una alternativa unitaria que le permitiera seguir impulsando la política de ruptura. Esa alternativa unitaria se llamó junta democrática y estuvo integrada por los comunistas del PCE, por pequeños grupos de socialistas, carlistas y políticos independientes.

En Cataluña, l'Assemblea de Catalunya ${ }^{28}$ y las fuerzas políticas y sociales que la integraron también prosiguieron su tarea unitaria en una línea de ruptura democrática.

En este ambiente político apareció la declaración de la coordinadora general de CCOO (enero de 1974). En ella se criticó la política económica del gobierno porque engendraba inflación; también se le criticó por querer congelar los sueldos a través de topes salariales.

En ese manifiesto se apeló a los trabajadores a desarrollar una fuerte lucha para conseguir el aumento inmediato de los salarios, el establecimiento de la escala móvil, la semana laboral de 40 horas, el 100\% del salario real en caso de accidente, enfermedad o jubilación, a igual trabajo igual salario, establecimiento de medidas de seguridad en el trabajo, derecho de reunión, de asamblea y de huelga, que se sobreseyeran a todos los procesados (se pronunció por la redención de los 10 encarcelados en el proceso 1001) ${ }^{29}$ y que hubiera amnistía, libertades sindicales y políticas.

También abogó por utilizar mejor las posibilidades legales de lucha y enlazarlas con las acciones extralegales, acrecentando, así, la envergadura de las luchas obreras con el fin de abrogar la dictadura.

Finalmente invocó a todos los grupos, partidos políticos y movimientos de masas a establecer un consenso para conseguir la amnistía general, el restablecimiento de las libertades sindicales, el derecho de huelga, las libertades políticas y el respeto a los derechos nacionales de los pueblos.

28. surgió en noviembre de 1971. Fue la máxima expresión de un proceso de convergencia entre las fuerza de la oposición en Cataluña. Aglutinó a partidos clandestinos, a representante de movimientos sociales como las asociaciones de vecinos, grupos culturales nacionalistas y colectivos obreros organizados. Demandó la amnistía para los presos políticos y exiliados, libertades democráticas, derecho de huelga y la restauración de la autonomía de Cataluña

29. juicio que se celebró en diciembre de 1973 por la detención en junio de 1972 en Madrid de los líderes de comisiones obreras en un convento del barrio madrileño de pozuelo, cuando, en asamblea nacional, se tenía que discutir un nuevo documento sindical, que trataba de cómo evitar que comisiones obreras se dividieran en diferentes tendencias. 


\section{El parecer de las restantes tendencias de CCOO}

En enero de 1974, "sectores" de comisiones obreras del Baix Llobregat, pertenecientes a la organización Bandera Roja juzgó que para que el movimiento obrero saliera victorioso en su contienda contra la patronal era necesaria la realización de asambleas en todas las fábricas, tomándose en ellas las decisiones más importantes y extenderlas al resto de las empresas para que las conocieran. Opinó que en las luchas debían participar el mayor número de trabajadores. Creyó, también, que se tenían que difundir las luchas al resto de las fábricas. Pensó que era necesario que la población convergiera con las luchas obreras, para lo cual era necesario concentrarse y manifestarse en la calle.

Estimó que era imprescindible utilizar al máximo las posibilidades legales: cargos sindicales y asambleas de ramo en la OSE ${ }^{30}$ para así contribuir a conseguir objetivos concretos en el avance del movimiento obrero. Se manifestó contra el coste de la vida y demandó 4.000 Ptas. de aumento mensual, IRTP y seguridad social a cargo de la empresa, 40 horas semanales, ayuda escolar, 30 días de vacaciones, $100 \%$ del sueldo en caso de enfermedad o jubilación, no a los contratos eventuales. También se pronunció por el derecho de asamblea ${ }^{31}$.

La otra tendencia de CCOO "plataformas anticapitalistas", constituida por militantes de extrema izquierda, fue partidaria de que la clase obrera saliera del marco legal, que abdicase de la OSE, de los enlaces, jurados y de los convenios colectivos porque ese camino era estéril para su emancipación. Juzgó que el órgano soberano de discusión, elaboración y control era la asamblea de fábrica (en sustitución de la OSE) y que en ella se elegirían comisiones representativas y revocables que ejecutarían lo decidido en la asamblea (estas comisiones representativas sustituirían a los enlaces y jurados). Apeló a los trabajadores a que lucharan contra el capitalismo. Reivindicó 4.000 ptas. de jornal mínimo semanal, la eliminación del IRTP, el pago por parte del empresario de las cuotas de la seguridad social, 40 días de vacaciones, no a los contratos eventuales y al sistema de primas y cronometrajes ${ }^{32}$.

Pero esta tendencia, por las razones ya expuestas, tuvo poco eco en el Baix Llobregat, aunque en el Vallés oriental consiguió atraerse, a partir de 1971, a obreros inmigrantes jóvenes; pero su militancia fue efímera ${ }^{33}$. En 1976, esta tendencia de CC.OO. tuvo relevancia en la huelga que realizaron los trabajadores de la empresa Roca de Gavá.

30. Organización Sindical Española. Es el nombre que recibió el sindicato vertical después de la ley sindical de 1971

31. Anónimo, la represión se perfecciona; En la comarca... ¿Qué hacer?, en "Prensa obrera", 1974 , n. 16 , pp. 4 y 5.

32. API, 1974, no 49.

33. Cfr. S. Balfour, Dictatorship, wrkers and the city. Labour in Greater Barcelona since 1939, Oxford, Oxford University Press, 1989 [ tr. Esp. La dictadura, los trabajadores y la ciudad. El movimiento obrero en el Área Metropolitana de Barcelona (1939-1988), Valencia, Edicions Alfons el Magnànim, 1994, P.176]. 


\section{Conflictividad laboral en 1974}

El mes de enero empezó con el desacuerdo de muchos trabajadores con las deliberaciones de sus convenios. En muchas fábricas se reclamaron 30 días de vacaciones, el 100\% del sueldo en caso de enfermedad, accidente o jubilación, 40 horas de trabajo a la semana, IRTP a cargo de la empresa y aumento salarial que oscilase entre las 3.500 ptas. y las 5.000 ptas al mes.

Los trabajadores de Elsa (empresa ubicada en Cornellá y perteneciente al ramo del vidrio, con 960 trabajadores) reivindicaron en su convenio 5.000 ptas. de aumento al mes, IRTP y seguridad social a cargo de la empresa, 30 días de vacaciones, $100 \%$ del sueldo en caso de enfermedad, accidente o jubilación, no a la eventualidad y a los aumentos de ritmos de trabajo. La empresa contestó el 15 de enero presentando la siguiente oferta: aumento de 2.400 ptas. al mes, que se perdería en caso de trabajar a un ritmo inferior; que determinado personal trabajara obligatoriamente un domingo al mes a cambio de 600 ptas. Concedía, también, un incremento del salario en caso de enfermedad situado entre el $25 \%$ y el $50 \%$, pero con la condición de que un médico de la empresa visitara el trabajador. El día 18 de enero los trabajadores se reunieron en asamblea y rechazaron la oferta de la empresa, decidiendo luchar por sus reivindicaciones. Iniciaron paros parciales el 21 de mayo.

Los trabajadores de Solvay (empresa ubicada en Martorell y perteneciente al ramo de la química) se desavinieron con la dirección de la empresa a causa de la revisión del convenio. La dirección ofrecía el 6’5\% de aumento salarial y ellos exigían 6.000 ptas. al mes. Los mandos de la empresa se negaron a la petición de los trabajadores. Ante ese rechazo los trabajadores se volvieron a reunir en asamblea y acordaron abaratar la demanda de subida salarial a 3.500 ptas. mensuales; pero la empresa continuó rehusándola. Como consecuencia de la negativa empresarial se realizaron paros parciales en el mes de mayo.

Por otra parte, los empresarios del metal del Baix Llobregat se negaron a renegociar el convenio local e intentaron imponer el provincial que recogía niveles salariales y condiciones mucho peores que el anterior, rechazando, de esa manera, la plataforma reivindicativa de los trabajadores consistente en 650 ptas. diarias de sueldo mínimo, 40 horas de trabajo a la semana, IRTP a cargo de la empresa y derecho de asamblea y huelga ${ }^{34}$.

El descontento de los trabajadores metalúrgicos del Baix Llobregat coincidió con las huelgas de los trabajadores de las empresas Elsa y Solvay. Por otra parte, los enlaces sindicales del metal, reunidos en asamblea general en los locales de la OSE, convocaron un paro de dos horas en la industria del sector

34. En una octavilla firmada por la coordinadora unitaria de CCOO del Baix Llobregat se incluía el derecho a la libre sindicalización y contra el gobierno Arias-franquista:"que con falsas aperturas quiere continuar negando las mínimas libertades políticas", v. En ANC, RMV. 
metalúrgico para el 3 de julio. Sin embargo, al día siguiente, reunidos nuevamente en los locales del sindicato vertical, acordaron convocar una huelga general que vinculó las luchas de los trabajadores de Elsa y Solvay. Ese paro se convirtió en huelga general el 4 de julio al sumarse los trabajadores de los talleres y fábricas pequeñas por requerimiento de los obreros que ya habían parado. La huelga general continuó el día 5. Según El Correo Catalán el 80\% de las empresas de Cornellá estuvieron en paro, junto con los bares y comercios de la ciudad. También pararon los trabajadores de otros municipios del Baix Llobregat como San Feliu, San Joan Despí, Espulgues y San Boi.

El resultado de la huelga de Elsa significó, para los trabajadores, la concesión de mejoras económicas en cuantía global anual de 40 millones de pesetas distribuidas en diferentes formas: revisión de salarios a primero de enero de 1975 y a primero de julio del mismo año, concesión de 800 ptas. de prima especial a todos los trabajadores que voluntariamente quisieran trabajar el tercer domingo consecutivo y la readmisión de todos los trabajadores, con excepción del primer despedido y del secretario del jurado de empresa, que voluntariamente rescindió su contrato de trabajo en el acto de firma del pacto. De todos modos, la OSE se comprometió a encontrarle empleo ${ }^{35}$.

Según Sebastián Balfour ${ }^{36}$ la consecuencia de la huelga general de la comarca del Baix Llobregat fue el fortalecimiento de CCOO, la incorporación de los nuevos líderes antaño indiferentes y la radicalización de los enlaces sindicales más moderados.

Los trabajadores de Pirelli-Moltex (empresa química de Cornellá con 780 trabajadores) decidieron, en asamblea, parar dos horas en días alternos durante la tercera semana de enero de 1974 por desaprobar la empresa su plataforma reivindicativa para el próximo convenio. En esta plataforma se exigió 3.500 ptas. para todos, 30 días de vacaciones, $100 \%$ del sueldo en caso de enfermedad, accidente o jubilación y 40 horas semanales.

Éstos, el 20 de septiembre del mismo año, realizaron la huelga más larga de su historia (duró 25 días) al rechazar la dirección la nueva petición de aumento mensual de 2.000 Ptas.

Ante la intransigencia de la empresa, el 14 de octubre se reunió un importante grupo de cargos sindicales en los locales de la OSE y acordaron realizar un paro solidario de dos horas de duración para el siguiente día, 15 de octubre, en protesta por la actitud de la empresa (Pirelli-Moltex) por no querer acceder a las reivindicaciones de los trabajadores y sancionarlos ${ }^{37}$.

35. J. De Hoyos, S.A. Elsa: la huelga más larga, Barcelona, informa sindicatos, 1974, passim.

36. Op. cit., p. 224.

37. Actas de jurados de empresa, 15 de octubre de 1974. Depósito de Archivos de Cervera. Ese paro incluyó también a los trabajadores de Fundiciones Ros, S.A. de Sant Vicens del Horts. 
La segunda huelga general en la comarca aconteció los días 5, 6 y 7 de diciembre de 1974. Se acordó en una asamblea de 500 cargos sindicales del Baix Llobregat el día 28 de noviembre en los locales de la OSE.

El paro general fue en contra de la carestía de la vida y tuvo por finalidad descomponer al régimen. En un principio se quiso que sólo tuviera una duración de 24 horas. Pero al ser detenidos veinticuatro líderes obreros, por parte de la policía, en un intento de impedir la huelga en la madrugada del 3 al 4 de diciembre, se prolongó tres días.

Francisco Ruiz Acevedo dice a este respecto que:

En diciembre de 1974 se produjo la segunda huelga general. Fue política porque era contra la carestía de la vida. Empezó al día siguiente porque, la noche anterior, la policía detuvo a veinticuatro dirigentes obreros (todos éramos del Baix Llobregat) y la mayoría militábamos en el P.S.U.C.; como consecuencia, al otro día pararon 80.000 trabajadores. No sólo pararon, sino que salieron a la calle.

Digo que fue una huelga política porque luchar contra la carestía de la vida significaba y de hecho se convertía en una lucha contra la política económica del gobierno.

\section{Estrategia y objetivos de CC.OO. en 1975}

Ante la efervescencia política que vivió el país como consecuencia de la presión que ejerció la oposición antifranquista a través de los movimientos de masas, la CONC ${ }^{38}$ (Comisión Obrera Nacional de Cataluña) manifestó en enero de 1975 su propósito de luchar con ahínco para conseguir el cambio democrático. Apeló a que hubiera un ascenso en las luchas obreras para conseguir la readmisión de todos los despedidos, el aumento de los salarios, las libertades sindicales, políticas y la amnistía ${ }^{39}$.

Muerto el dictador la CONC criticó la próxima coronación del rey Juan Carlos por considerar este acontecimiento una perpetuación del régimen y llamó a los trabajadores a ir a la huelga general el 11 de diciembre para abrogar la dictadura e imponer la amnistía y la democracia parlamentaria.

En la comarca del Baix Llobregat pararon, ese día, 70 empresas durante 4 h.. No sólo por la amnistía, sino también en solidaridad con los trabajadores despedidos de la empresa Laforsa, ubicada en Cornellá ${ }^{40}$.

38. fue el órgano máximo de representación del movimiento socio-político de CCOO. Estaba compuesto por delegaciones de las distintas comarcas de Cataluña. Se creó en 1966

39. La coordinadora general de plataformas anticapitalistas de CCOO llamó a los trabajadores a ir a la huelga el 5 de febrero para conseguir el pleno empleo y la abrogación de la eventualidad, subidas salariales de 7.000 ptas., eliminación del IRTP y el pago, por parte de las empresas, de la seguridad social, la semana laboral de 40 horas, la liberación de todos los detenidos y la imposición en las fábricas de las asambleas y comisiones representativas, v. en ANC, RMV.

40. cfr. Ignasi Riera y José Botella, op. cit., p. 175. 


\section{Elecciones sindicales de 1975}

CCOO presentó en las elecciones sindicales de junio de 1975 una candidatura unitaria con el fin de alcanzar el mayor consenso posible llamada "Candidaturas Unitarias Democráticas". En el Baix Llobregat su programa incluyó un aumento de 3.000 ptas. mensuales, 40 horas de trabajo a la semana, derecho de huelga, amnistía para los presos políticos y sociales, sindicato obrero de clase, libertad sindical, de reunión, de expresión y asociación, construcción de ambulatorios, escuelas y viviendas ${ }^{41}$.

Esa candidatura ganó las elecciones sindicales de junio de 1975 y en ellas participaron el 92\% de los trabajadores de la mencionada comarca. El 63\% de los representantes sindicales de las Candidaturas Obreras de Renovación Democrática eran menores de 40 años, y el 12\% eran mujeres. Las presidencias y vicepresidencias de las diferentes Uniones de Técnicos Trabajadores fueron ocupados por militantes del PSUC ${ }^{42}$.

En las fábricas más grandes de Barcelona ciudad también ganaron las CCOO. Según el diario El Mundo con fecha 28 de junio de 1975:" En las 30 empresas más importantes de Barcelona, los candidatos democráticos ganaron en todas excepto en tres. De más de un millar de delegados, las listas oficialistas e independientes habían conseguido sólo 188 candidatos electos $^{\prime{ }^{43}}$

En el Baix Llobregat el movimiento obrero (siguiendo la política oficial del PSUC de destruir la OSE desde dentro como proceso de ruptura democrática) se hizo con el control del sindicato franquista.

Los cargos sindicales electos manifestaron su aspiración de conseguir la libertad sindical; y que se reconociera al futuro sindicato como un ente obrero, unitario, democrático e independiente ${ }^{44}$.

En el Baix Llobregat se creó una intersindical que aglutinó a todos los representantes electos de la comarca. En este ente se intentó conjugar representatividad

41. Joan Tardà y Pedro Carrión, op. cit., p. 173.

El boicot a las elecciones sindicales lanzada por la Liga Comunista Revolucionaria no surtió efecto. Ese partido abogó porque las candidaturas fueran decididas en asamblea, v. Anónimo, Boicot a las elecciones sindicales, en "Proletariado del Baix Llobregat", 1975, nº 2, pp. 8 y 9.

La UGT, igualmente con muy poco peso entre los trabajadores, también boicoteó las elecciones de 1975.

42. J. Tardà y P. Carrión, ibídem.

43. citado por S. Balfour en op. cit., p. 228.

44. Las plataformas anticapitalistas del Baix Llobregat (sector minoritario de CCOO) desearon que esta organización unitaria estuviera basada en la asamblea de cada fábrica y que en ella se eligiera a los representantes o delegados, siendo revocables en el momento que no cumpliera las funciones que la asamblea les había delegado; pero este sector de CCOO apenas tuvo incidencia en el movimiento obrero de la comarca, v. i contra la división sindical. La unidad obrera. Construyamos la central única de trabajadores, en ANC, RMV. 
obrera, coordinación a nivel comarcal y ruptura con las instituciones verticales; pero siempre desde un marco unitario y democrático ${ }^{45}$.

\section{El conflicto de la fábrica Laforsa y la tercera huelga general}

La huelga que realizaron los trabajadores de Laforsa (empresa metalúrgica de Cornellá, con 193 trabajadores) empezó el 11 de noviembre de 1975, pero el conflicto entre los obreros y la dirección de la empresa comenzó antes. El 25 de agosto los trabajadores de la empresa, al disminuírseles las primas de producción, que pactaron con los gestores de la fábrica, decidieron en asamblea dejar de hacer horas extra, trabajar en días festivos y no realizar las reducciones de jornada; al mismo tiempo declararon conflicto colectivo por cauces legales y lo presentaron a los sindicatos el día 27 de agosto.

La empresa despidió injustificadamente a un trabajador el 11 de noviembre. Ese fue el motivo inmediato de la huelga, que empezó ese día y duró 105 días.

Los 107 obreros, que esa fábrica dejó en la calle, redactaron un informe el 19 de noviembre que explicaba las causas del conflicto y finalizaba demandando un sindicato obrero, unitario, representativo, democrático e independiente. También el reconocimiento del derecho de huelga ${ }^{46}$.

En diciembre, la UTT (Unión de Trabajadores y Técnicos) del metal expresó, a través de una hoja informativa, su solidaridad con los obreros de Laforsa y con los de otras fábricas de la comarca: Fapasa (de Esplugues), Fama (de Cornellá), Soler Almirall (de Sant Joan Despí). Ese documento finalizó reivindicando un salario mínimo de 20.000 ptas. mensuales para los trabajadores del sector, no a las horas extras porque robaba puestos de trabajo a los parados, la jornada laboral de 40 h., y condiciones de seguridad e higiene adecuadas ${ }^{47}$.

El 11 de diciembre CCOO convocó un paro general en solidaridad con los obreros despedidos de la fábrica Laforsa. Ese día pararon, durante 4 h., 70 empresas de la comarca ${ }^{48}$.

En enero de 1976, la intersindical acordó proponer una semana de lucha en solidaridad con los trabajadores de Laforsa, contra los topes salariales, por la

45. I. Riera y J. Botella, op. cit., p. 174.

46. Informe y valoración del conflicto colectivo desarrollado por los trabajadores de la empresa Laforsa, 19 de noviembre de 1975, v. en ANC, RMV.

47. Readmisión de los despedidos. Conservar el puesto de trabajo, s/f, en ANC

48. Ignasi Riera y José Botella, op. cit., p.175.

49. op., cit., pp. 180 y 181. 
defensa de los puestos de trabajo y por la amnistía. Esa semana de huelga general transcurrió entre los días 19 y 25 de enero.

Según Ignasi Riera y José Botella ${ }^{49}$, durante esa semana hubo un promedio de 60.000 huelguistas diarios y se perdieron 5 millones de horas/hombre de trabajo. Esos historiadores continuaron diciendo que se sumaron a la huelga todas las poblaciones de la comarca sindical de Cornellá, más Esplugues y Sant Just Desvern, las cuales pertenecían a la comarca sindical de I'Hospitalet, y una serie de poblaciones de la comarca sindical de Martorell.

Soledad Bengoechea y Mercè Renom ${ }^{50}$ enumeran la cifra en más de 40.000 obreros huelguistas (según la Delegación Provincial de Sindicatos), 60.000 (según la intersindical) y 80.000 (según otras fuentes).

A finales de febrero, la dirección de la empresa de Laforsa readmitió a los obreros despedidos.

A principios de 1976, una vez muerto el dictador, se entabló una polémica en el seno de CCOO del Baix Llobregat, que enfrentó a dos tendencias: los que defendieron la necesidad de suprimir el movimiento unitario de CCOO en pro de las Candidaturas unitarias y democráticas para, desde el interior de la OSE, ir configurando la central única de trabajadores y los que defendieron la necesidad de mantener y potenciar las estructuras de CCOO, porque juzgaban que la experiencia del Baix Llobregat no se podía trasladar a otras comarcas y ciudades. Éstos últimos opinaban que en otros sitios el movimiento socio-político de CCOO estaba más debilitado y esas candidaturas unitarias fracasarían. Al final ganó la segunda postura. Sin embargo, todos los militantes de CCOO del Baix Llobregat apostaron por la unidad sindical, porque pensaban que la pluralidad sindical dividía a los trabajadores y que los sindicatos se convertirían en los portavoces de los partidos políticos. Pero con el tiempo el movimiento socio-político de CCOO se convirtió en un sindicato.

\section{Conclusión}

CCOO del Baix Llobregat fue independiente del PSUC, a pesar de que muchos de sus militantes estuvieran afiliados a ese partido político ${ }^{51}$. Sus decisiones no las tomó el PSUC, sino los trabajadores que estaban en ese

50. op., cit, p. 266.

51. La coordinadora de CCOO del Baix Llobregat, que se creó en otoño de 1965 estuvo compuesta por catorce trabajadores, once de los cuales militaban en el PSUC, uno en la HOAC (Hermandad Obrera de Acción Católica) y otro en ACO (Acción Católica Obrera). 
movimiento socio-político obrero ${ }^{52}$. Francisco Ruíz Acevedo dice al respecto: "las decisiones en CCOO del Baix Llobregat no las tomó el PSUC, sino los militantes que estaban en $\mathrm{CCOO}$, muchos de los cuales no militaban en aquel partido político". José Cano dice:" el PSUC no implantó su política en CCOO del Baix Llobregat. CCOO tuvo libertad de pensamiento y de acción"

A partir de 1970 aumentó la conflictividad laboral. Fue a partir de ese año cuando se incorporaron las demandas políticas a las reivindicaciones laborales de los trabajadores para, de esa forma, acabar con la dictadura e instaurar la democracia parlamentaria; pero hasta 1975 sólo la mitad de los obreros del Baix Llobregat fueron receptivos a esa reclamación. La otra mitad se preocupó más por los requerimientos económicos y sociales. De todos modos, las huelgas por motivos económicos y políticos se entrelazaron entre sí a causa de la naturaleza autoritaria del régimen ${ }^{53}$. Francisco Ruíz Acevedo dice:

Las huelgas por motivos económicos, laborales y políticos estaban entrelazadas. Empezaban por reivindicaciones económicas, pero rápidamente se politizaban porque había represión y eso hacía que los obreros rápidamente tomaran conciencia política. Veían que el problema no radicaba en su empresa, sino en el propio régimen. Todo estaba entretejido: reivindicación, represión y solidaridad era un efecto que provocaba el régimen político existente

Hay que decir, también, que los trabajadores técnicos y administrativos se involucraron menos en las luchas obreras de la comarca porque tenían mejores condiciones económicas y laborales..

La conflictividad laboral en el Baix Llobregat fue, fundamentalmente, consecuencia de la renovación de los convenios colectivos. Las empresas que mostraron más oposición obrera fueron de tamaño mediano y grande ${ }^{54}$. Francisco Ruíz Acevedo dice que:

52. Sebastián Balfour dice al respecto lo siguiente:

En esta dicotomía entre libertad de acción y centralismo democrático estuvo la clave del comportamiento de los activistas obreros del PSUC. El discurso político del partido, preocupado por las grandes estrategias de la organización, generalmente no se vinculó al trabajo cotidiano de los militantes. Por ello era menos probable que desafiaran la línea del partido, que les dejaba libres para desarrollar sus propias prácticas sobre materias que conocían muy de cerca. [...]

En cualquier caso, las tareas políticas que el partido asignaba a la Comisiones Obreras inevitablemente acabaron diluyendo la presencia del partido en las fábricas. [...]

Los activistas obreros del PSUC, pues, tenían dos funciones diferentes, la de organizadores en las fábricas tratando a diario con las cuestiones sindicales, y la de líderes políticos que defendían la línea del partido. Las dos causas no siempre se complementaban. Además, pese a todos los alegatos sobre la independencia de las Comisiones, la casi completa hegemonía de los comunistas a menudo llegó a hacer borrosa la distinción entre el partido y el movimiento. Los militantes frecuentemente se desdoblaron como agitadores sociales y como portavoces del partido. cfr. en op. cit., pp. 178, 179 y 180.

53. cfr. A. Soto Carmona, huelgas en el franquismo: causas laborales-consecuencias políticas, en "Historia social", 1998, n. 30, pp. 39-40.

54. cfr. Idem, op. cit., p. 56. cfr. También X. Doménech Sampere, El problema de la conflictividad bajo el franquismo: saliendo del paradigma, en "Historia social", 2002, n. 42, p.132. 
En el Baix Llobregat quienes tiraban del movimiento obrero eran las empresas grandes [entiende por empresas grandes aquéllas que tienen más de 100 trabajadores] porque los obreros estaban más organizados, tanto ilegalmente en $\mathrm{CCOO}$, como legalmente, esto es, tenían más enlaces sindicales y jurados de empresa, que aun no militando en CCOO secundaban su política.

José Cano opina lo mismo.

La patronal fue muy intransigente en la negociación: despidió a trabajadores, lo cual provocó huelgas solidarias.

Los conflictos laborales se trasladaron, en la mencionada comarca, fuera del ámbito de la fábrica. Se extendieron a sectores de la población no involucrados directamente en los mismos, como comercios, bares, institutos...

Las luchas obreras de la comarca acontecieron en la zona meridional (a excepción de Martorell en la huelga de Solvay de 1974).

En 1975 el movimiento obrero del Baix Llobregat consiguió una ruptura democrática en el mundo fabril y se hizo con el control del sindicato estatal; pero no se dio una situación revolucionaria: sus líderes sólo quisieron un cambio de régimen (veían la consecución del socialismo más a largo plazo) y la mayoría de los obreros no tuvieron una conciencia estrictamente socialista (las organizaciones a la izquierda del PSUC tuvieron poca resonancia). Las demandas logradas integraron a los trabajadores en la sociedad de consumo ${ }^{55}$.

55. cfr. S. Balfour, op. cit., pp. 233-245 